\title{
CONGENITAL THROMBOCYTOPENIC PURPURA
}

\author{
BY \\ K. HUGH-JONES, P. A. MANFIELD and H. F. BREWER \\ From the Departments of Paediatrics and Clinical Pathology, St. Bartholomew's Hospital, London
}

(RECEIVED FOR PUBLICATION MAY 29, 1959)

The purpose of this paper is to present four cases of neonatal thrombocytopenic purpura which have been investigated fully. Although an uncommon condition, it has aroused a good deal of interest and nearly 100 instances have been recorded to date. The literature has been reviewed by Robson and Walker (1951), who collected 52 cases and added three of their own, and also by Morris (1954), who gives references for a further 27 cases and also describes three more under her care. A detailed account of the condition is to be found in Stefanini and Dameshek's text-book The Hemorrhagic Disorders (1955).

The original classification of patients with congenital thrombocytopenic purpura into two main groups by Robson and Walker is now generally accepted as a helpful and practical division and is as follows:

Group I.-Infants born of mothers with thrombocytopenic purpura

(a) idiopathic type (I.T.P.), including mothers who had undergone splenectomy

(b) secondary or symptomatic type due to drugs, infections, toxaemias, etc.

Group II.-Infants born of normal mothers

Nevertheless this classification may be artificial since there are several instances on record (Sanford, Leslie and Crane, 1936; Urbanski and Hutner, 1942; Finn, 1944) illustrating that a woman may suffer from idiopathic thrombocytopenic purpura (I.T.P.) but be symptom-free and in remission during pregnancy and yet give birth to a thrombocytopenic infant. Unless repeated maternal platelet counts are carried out post-natally, such a case may be incorrectly assigned to Group II. An affected mother may give birth to a normal child (Finn, 1944) or may have dissimilar twins, one affected and one not (Goldstein, 1947). It is also possible that in these congenital cases a genetic fault is sometimes responsible and that fathers as well as mothers could be involved.
A more elaborate classification based on aetiology and illustrating the widely different mechanisms to which congenital thrombocytopenia may be attributable is that of Stefanini and Dameshek (1955). In this, cases are divided into two main groups according to whether megakaryocytes are absent or markedly reduced in the bone marrow (amegakaryocytic), or present in normal or increased numbers (megakaryocytic):

\section{Group I.-Amegakaryocytic}

(1) Congenital hypoplastic anaemia (including the Fanconi syndrome)

(2) Congenital hypoplastic thrombocytopenia

(3) Congenital acute leukaemia (usually granulocytic)

(4) Sepsis, congenital syphilis, other infections, viral diseases, etc.

Group II.-Megakaryocytic

(a) Children of non-thrombocytopenic mothers

(1) Idiopathic thrombocytopenic purpura (rarely present at birth) acute variety chronic variety

(2) Erythroblastosis foetalis with demonstrable platelet agglutinins

without demonstrable platelet agglutinins

(3) Platelet type incompatibility between mother and foetus

(b) Children of thrombocytopenic mothers

(1) Transplacental transfer of platelet agglutinins from mother to foetus (platelet agglutinins as a rule demonstrable in the mother's plasma)

(2) Drug thrombocytopenia (transfer through the placenta of both a plateletdestructive factor and the offending drug)

The four cases described in this paper were all the children of apparently healthy non-thrombocytopenic mothers. 


\section{Case Reports}

Case 1. (Fig. 1.) Paul B., a male child, was delivered at full term. The mother had had rubella at the eighth week of pregnancy and a purpuric rash appeared on the child's trunk, face and limbs within 15 minutes of birth (Figs. 2 and 3). He had various congenital defects, including penile hypospadias, a heart lesion and a cataract. On the first day after birth the platelet count was $56,000 / \mathrm{c} . \mathrm{mm}$.; the bone marrow showed very scanty megakaryocytes (Fig. 4) and those present had an atypical lymphoid appearance and seemed indolent as regards platelet production (Figs. 5 and 6); erythropoiesis was active; no platelet agglutinins were demonstrable in the infant's serum nor in the maternal serum put up against the infant's platelets. The platelet count after some fluctuation fell to $36,000 / \mathrm{c} . \mathrm{mm}$. on the eighth day. On the following day prednisolone was commenced and there was a satisfactory response in the platelet count which rose to normal and has remained normal since. A second marrow examination carried out about one month after birth, whilst the platelets were increasing, showed numerous megakaryocytes of normal morphology (Fig. 7). This child showed no significant anaemia.
Case 2. (Fig. 8.) Andrea H., a female child, was born at full term. About six hours after delivery a petechial rash was noted, mainly on the face and in the skin creases but also scattered over the trunk and limbs. Her initial platelet count on the second day was 96,000 / c.mm. The bone marrow on the third day showed a paucity of megakaryocytes; of those present some were of an intermediate type with granule formation whilst others were of the lymphoid variety, both devoid of platelet formation. Erythropoiesis was active. No platelet agglutinins were demonstrable in either the infant's or the mother's serum. The platelet count had dropped to $40,000 / \mathrm{c} . \mathrm{mm}$. by the fifth day when prednisolone was commenced. There followed a rapid rise in the platelet count which has remained normal. No anaemia was present.

Case 3. (Fig. 9.) Stella H., a second-born female child, was delivered at full term. Four days after birth she passed a small amount of blood per vaginam. Nine days after birth there was a large bruise on the left leg and it was noted that there was a tendency to bleed easily from a scratch over one eye. On the following day a small bruise appeared on the right leg. On the tenth

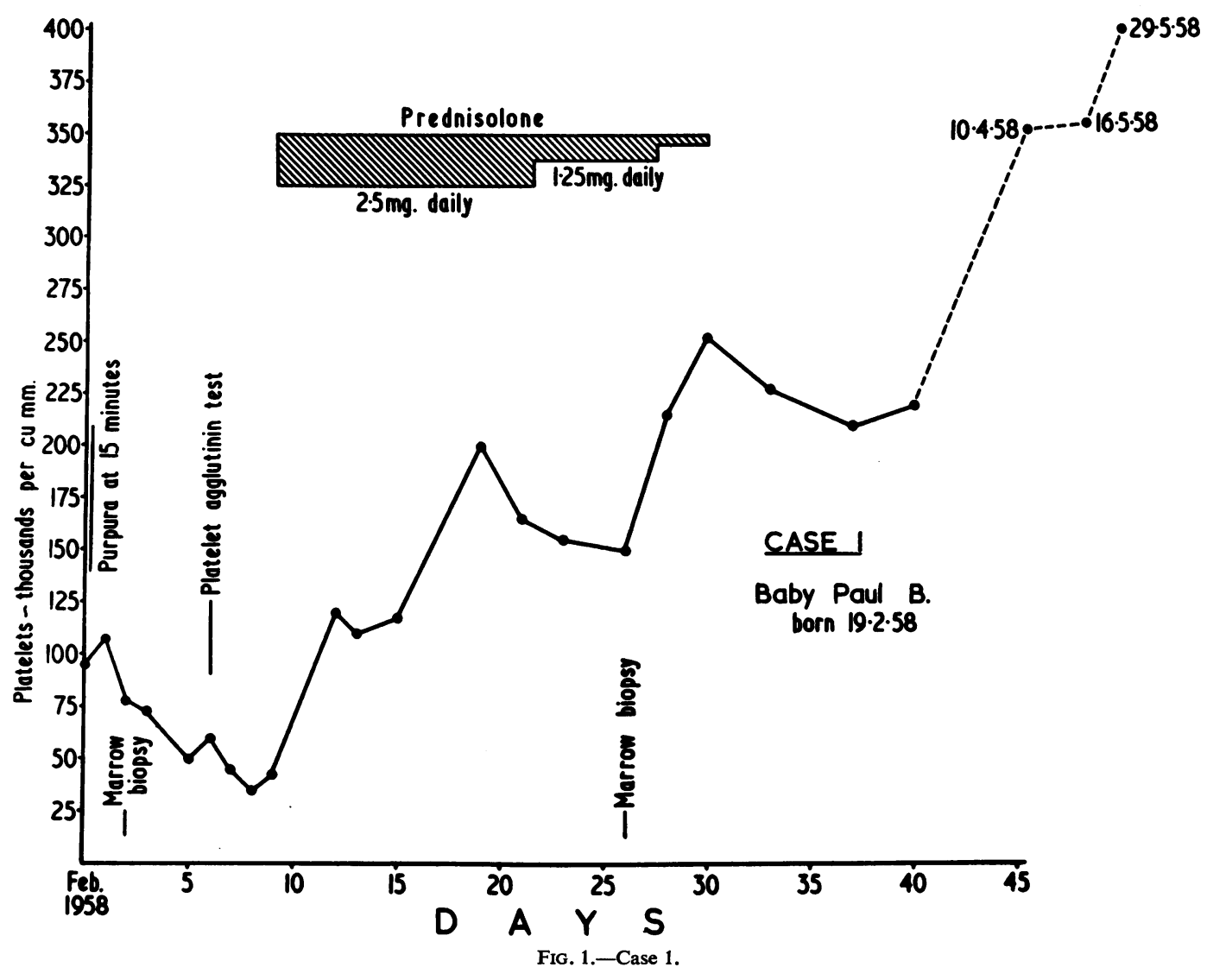




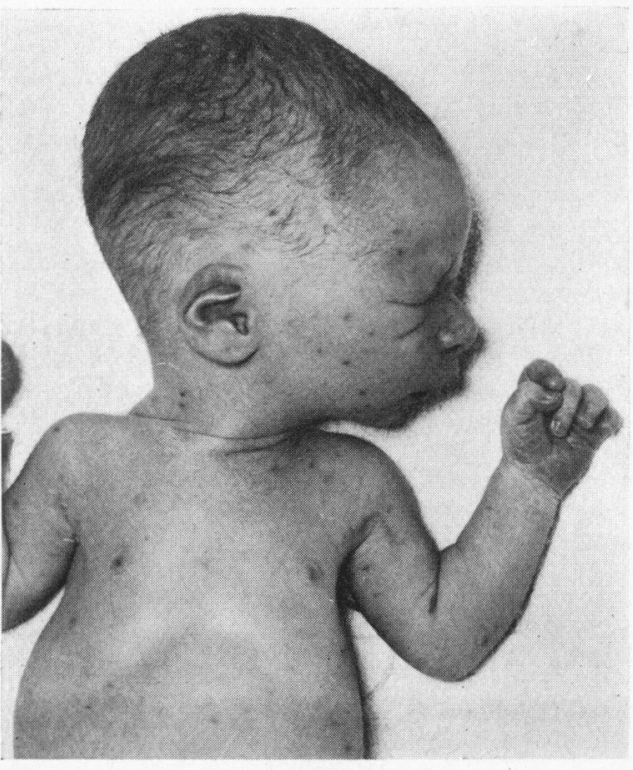

FIG. 2.

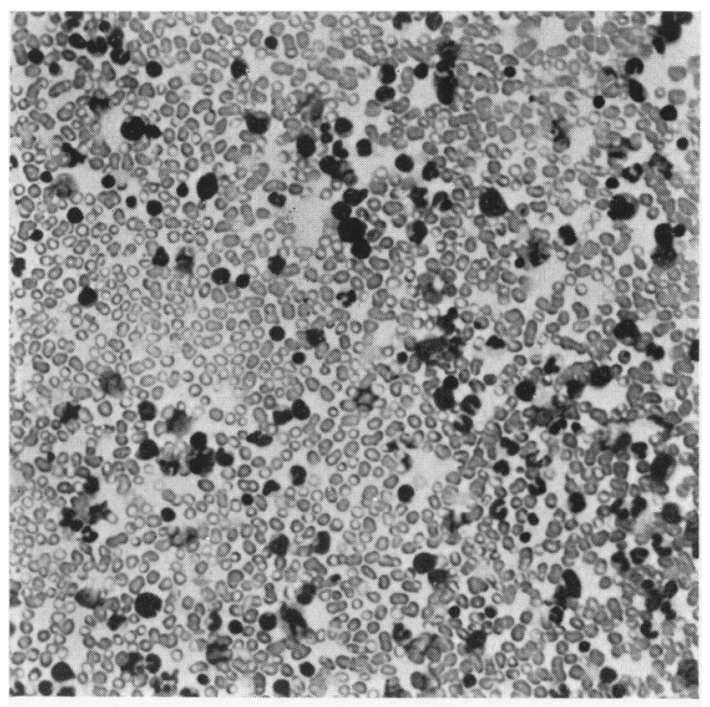

FIG. 4.

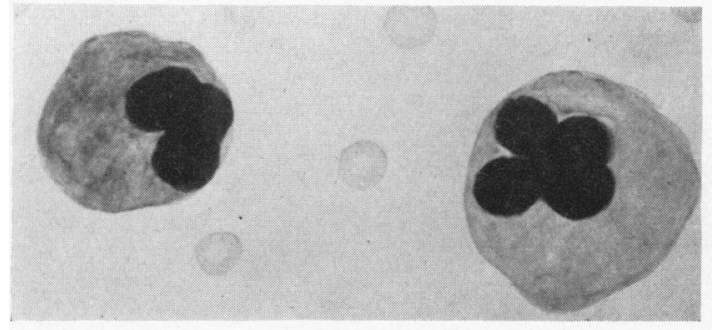

FIG. 5.

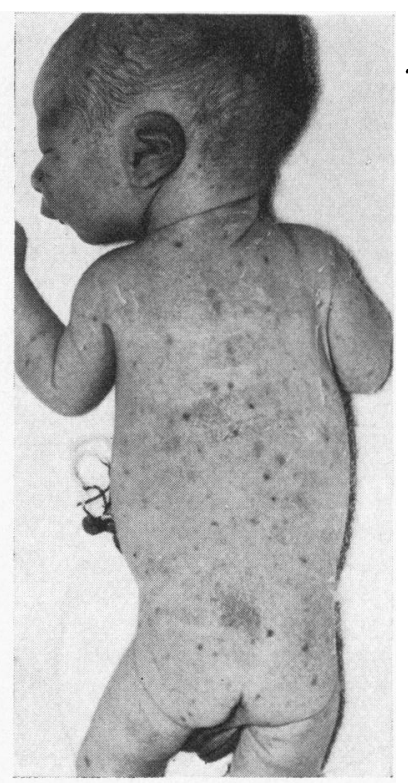

Figs. 2 and 3.-Case 1.

Fig. 4.-Case 1. Smear of tibial marrow taken one day after birth: $\times$ 175. (Marrow findings in Cases 2 and 3 during thrombocytopenic phase were similar.)

Figs. 5 and 6.-Case 1. Drawings of 'intermediate' and 'lymphoid' types of megakaryocytes present in

tibial marrow smear. $\times 800$.

Fig. 7.-Case 1. Smear of tibial marrow taken 26 days after birth when platelets had risen to 152,000 per c.mm. $\times 220$.

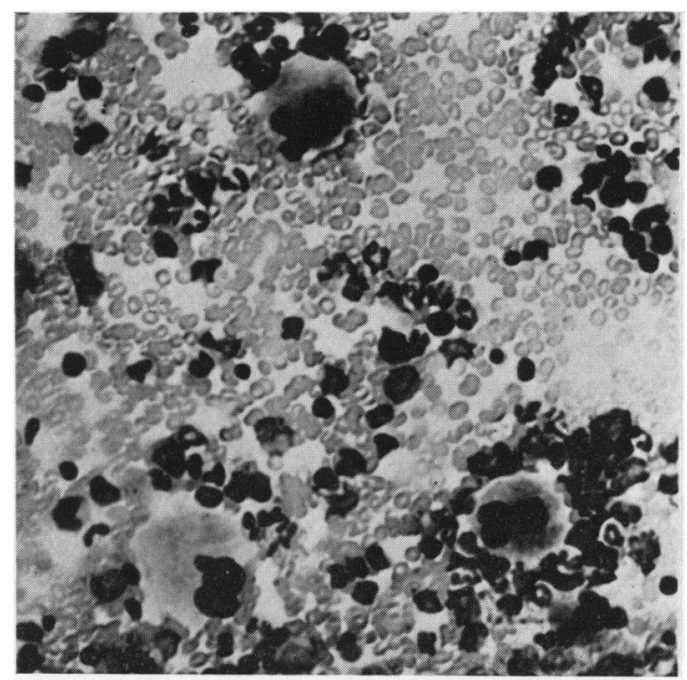

FIG. 7.

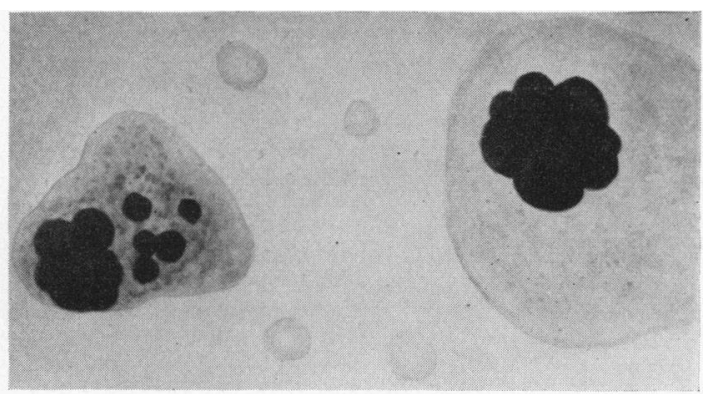

FIG. 6 


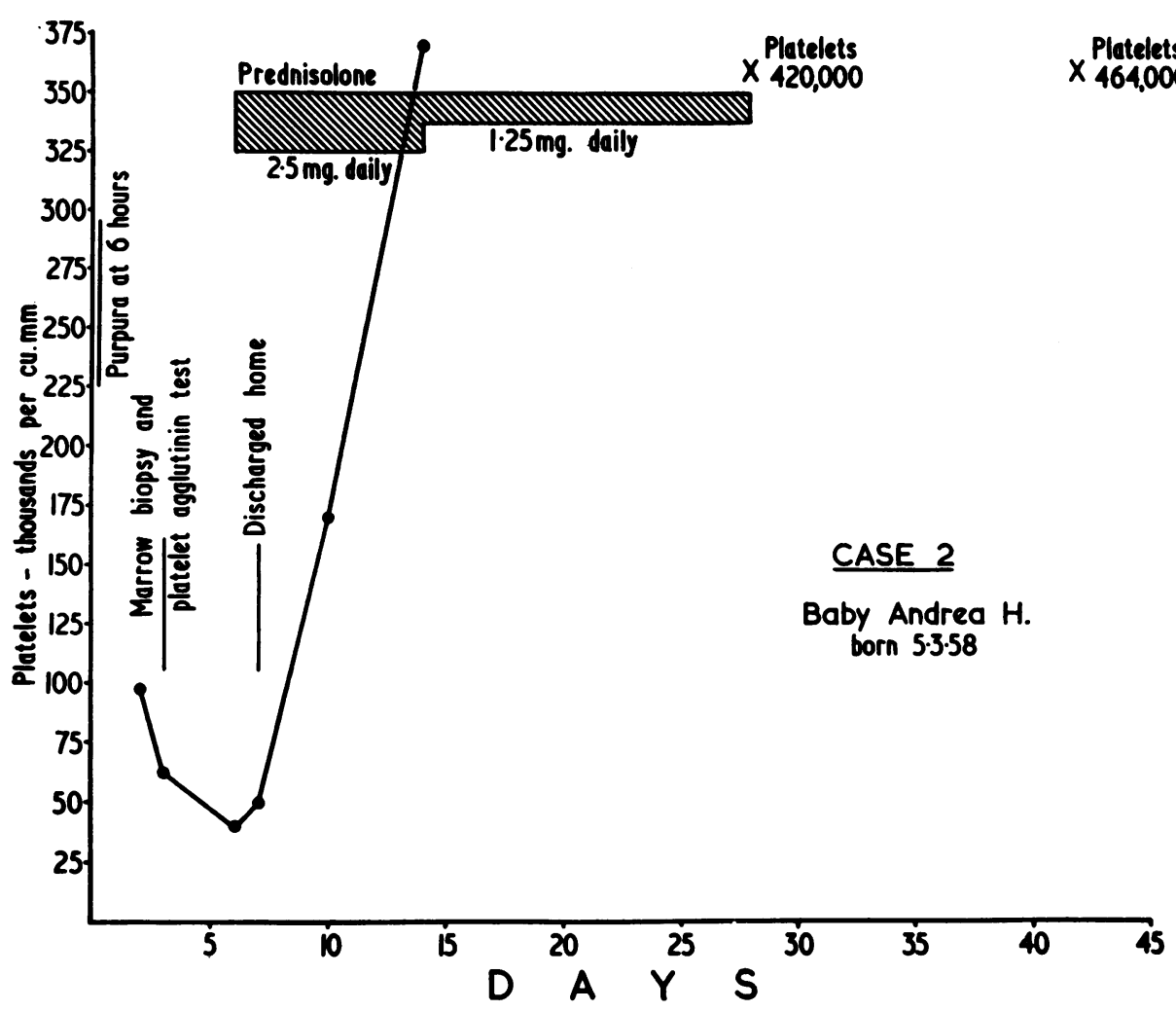

Fig. 8.-Case.2.

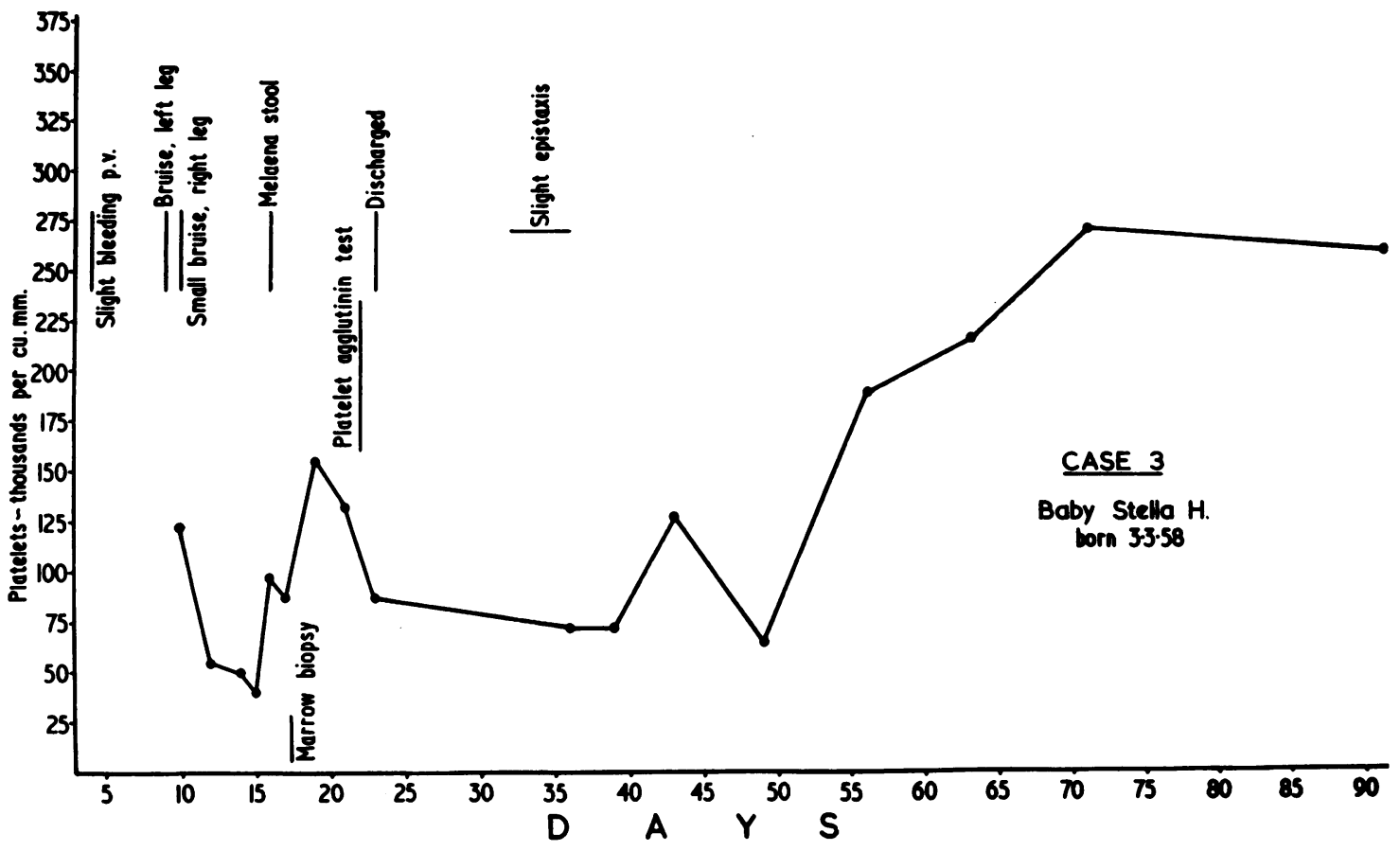

Fig. 9.-Case 3. 
day after birth the platelet count was $124,000 /$ c.mm., falling to $39,000 / \mathrm{c} . \mathrm{mm}$. during the succeeding five days. On the sixteenth day the child passed a melaena stool which soon cleared. No purpura was seen. A marrow examination carried out on the seventeenth day when the platelet count was $89,000 /$ c.mm. showed scanty megakaryocytes again of intermediate and lymphoid types with little platelet production. Platelet agglutinins against her own platelets and those of a normal compatible control were demonstrable in the infant's serum when tested on the twenty-second day of life but the maternal serum failed to agglutinate the child's platelets. These results were also confirmed in a subsequent test. The child was discharged aged 23 days and after some fluctuations in the platelet count, associated with mild epistaxis when it stood at $72,000 /$ c.mm., there was a gradual return to normal and the child had no haemorrhagic manifestations. She made a spontaneous recovery, no cortisone therapy being given.

Case 4. (Fig. 10.) Stephen $\mathrm{H}$. was a brother of the previous patient and was three and a half years older. They were the only children of the marriage. Eleven days after birth he had an epistaxis of three to four days' duration and the platelet count was found to be $83,000 /$ c.mm. It subsequently fell to $63,000 / \mathrm{c} . \mathrm{mm}$. and then rose quickly and spontaneously to a normal level, since when the boy has remained well. Tests carried out in April, 1958 showed a normal platelet count of 308,000/ c.mm., and no platelet agglutinins were demonstrable in his serum against his own platelets or those of a normal compatible control. The mother's serum also failed to agglutinate his platelets. No marrow biopsy was performed in the thrombocytopenic period shortly after birth and it was felt that no useful information would accrue by doing this after three and a half years when the boy was normal.

The familial aspect of these last two cases is very interesting.

Table 1 sets out the significant findings in the four cases described.

\section{Additional Significant Observations}

A family history of a bleeding tendency was obtained only in Cases 3 and 4 . In the six parents

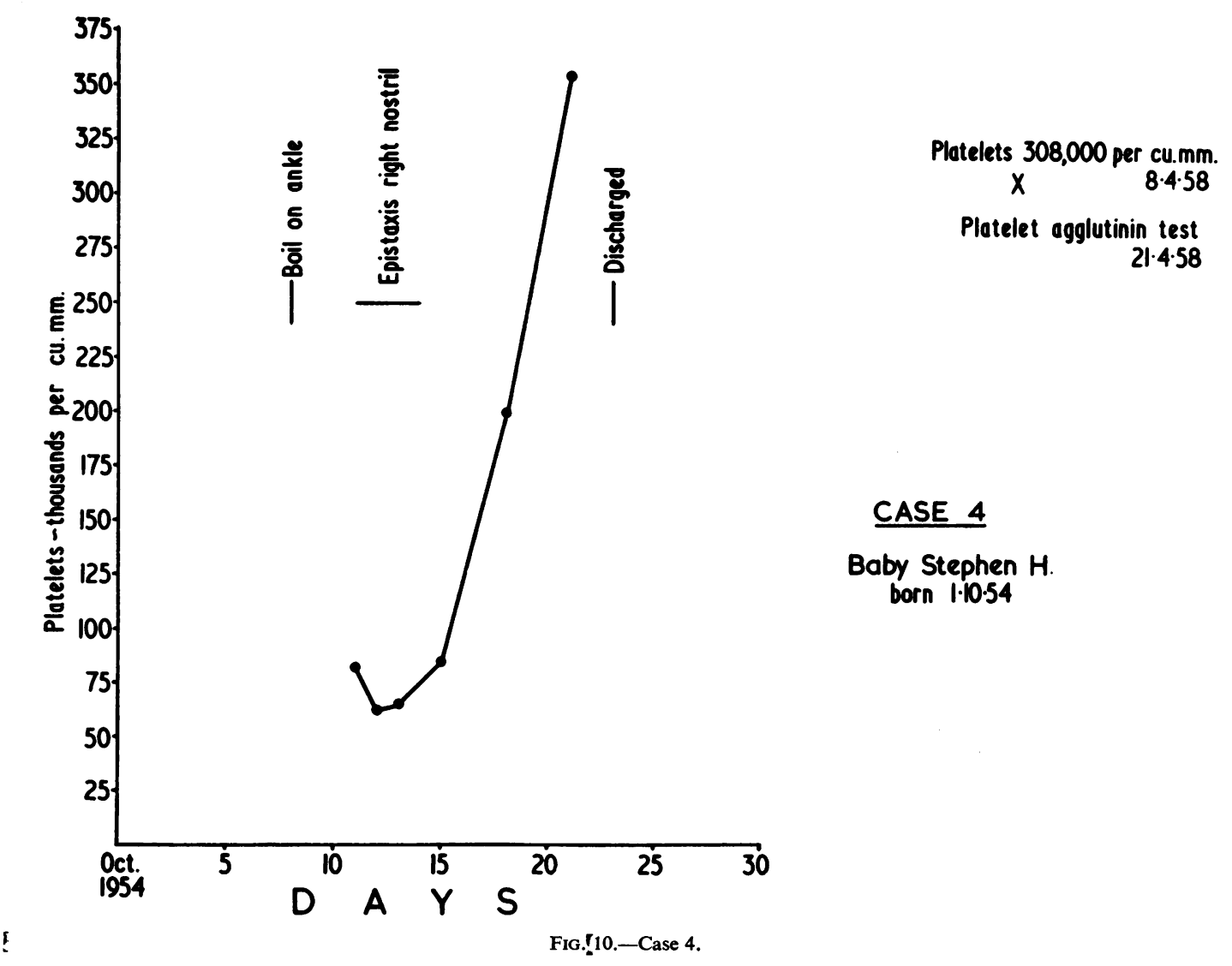


TABLE 1

CLINICAL DETAILS

\begin{tabular}{|c|c|c|c|c|c|c|c|}
\hline Case & $\begin{array}{l}\text { Age when } \\
\text { Lesions } \\
\text { Appeared }\end{array}$ & $\begin{array}{l}\text { Site of } \\
\text { Bleeding }\end{array}$ & $\begin{array}{c}\text { First and } \\
\text { Lowest } \\
\text { Platelet } \\
\text { Count } \\
\text { (no./c.mm.) }\end{array}$ & $\begin{array}{l}\text { Day of } \\
\text { Lowest } \\
\text { Count }\end{array}$ & $\begin{array}{l}\text { Marrow Biopsy } \\
\text { and Age }\end{array}$ & $\begin{array}{c}\text { Platelet } \\
\text { Agglutinations in } \\
\text { Infant and } \\
\text { Mother }\end{array}$ & $\begin{array}{l}\text { Mother's First Platelet } \\
\text { Count after Delivery } \\
\text { (no./c.mm.) and Day }\end{array}$ \\
\hline Paul $\stackrel{1}{\text { B. }}$ & $15 \mathrm{~min}$. & $\underset{\text { (purpura) }}{\text { Skin }}$ & $\begin{array}{r}56,000 \\
36,000\end{array}$ & 8 & $\begin{array}{l}\text { Megakaryocytes } \\
\text { present but scanty; } \\
\text { morphology as in I.T.P. } \\
\text { (1 day) } \\
\text { Megakaryocytes in } \\
\text { normal numbers; } \\
\text { morphology normal } \\
\text { (26 days) }\end{array}$ & None & 365,000 \\
\hline$\stackrel{2}{\text { Andrea } H .}$ & $6 \mathrm{hr}$. & $\underset{\text { (purpura) }}{\text { Skin }}$ & $\begin{array}{r}96,000 \\
40,000\end{array}$ & 5 & $\begin{array}{l}\text { Megakaryocytes } \\
\text { present but scanty; } \\
\text { morphology as in I.T.P. } \\
\text { ( } 2 \text { days) }\end{array}$ & None & 286,000 \\
\hline $\begin{array}{l}\text { Stella } \mathbf{H} . \\
\text { (sister of } \\
\text { (Case 4) }\end{array}$ & $\begin{array}{l}4,9,10,16, \\
32 \text { days }\end{array}$ & $\begin{array}{l}\text { Vagina, } \\
\text { skin } \\
\text { (bruising), } \\
\text { intestine, } \\
\text { nose }\end{array}$ & $\begin{array}{r}124,000 \\
39,000\end{array}$ & 15 & $\begin{array}{l}\text { Megakaryocytes } \\
\text { present but scanty; } \\
\text { morphology as in I.T.P. } \\
\text { (17 days) }\end{array}$ & $\begin{array}{l}\text { Present in } \\
\text { infant against } \\
\text { own platelets } \\
\text { and those of } \\
\text { normal control; } \\
\text { mother- } \\
\text { negative }\end{array}$ & $658,000 \quad(10)$ \\
\hline Stephen ${ }^{4}$. & 11 days & Nose & $83,000_{63,000}$ & 12 & Not examined & $\begin{array}{l}\text { Not tested at } \\
\text { birth; } \\
\text { none aged } \\
3 \frac{1}{2} \text { years }\end{array}$ & $386,000 \quad(12)$ \\
\hline
\end{tabular}

of the three families involved and in their relatives there was no suggestion of any haemorrhagic diathesis and platelet counts carried out on two or more occasions on each of the mothers were all within normal limits. No evidence of erythroblastosis foetalis was present clinically in any of the children shortly after birth. Anaemia was not a feature and the Coombs test in Cases 1, 2 and 3 was negative. All three mothers were Rhesus (D) positive, had negative Wassermann and Kahn reactions and were taking no drugs. Hypoprothrombinaemia was excluded and in none of the infants was there any prolongation of coagulation time. The spleen was palpable only in Case 1.

The purpura in the first two cases disappeared within a week to 10 days as the platelet count rose following the administration of prednisolone. In Cases 3 and 4 (sister and brother), where haemorrhage involved other sites, recovery was spontaneous and also rapid. The marrow biopsies were obtained by aspiration from the tibia. The platelets were counted by the Lempert technique, and platelet agglutinins were tested against suspensions of platelets in both saline and albumen.

\section{Discussion}

The four cases recorded were the offspring of apparently healthy non-thrombocytopenic mothers (Group II in Robson and Walker's original classification). Even allowing for the fact that a woman with idiopathic thrombocytopenic purpura (I.T.P.) may remit and be symptom-free during pregnancy, there was nothing to suggest this possibility in any of these mothers.

A marked reduction in megakaryocytes was a common feature in all three marrow examinations made during the early thrombocytopenic stage and this was unassociated with any general hypoplasia. This congenital hypoplasia of megakaryocytes accompanied by the morphological features already described suggests that the term 'congenital hypoplastic thrombocytopenia' may reflect the true nature of the condition and be a real entity (Hauser, 1948; Landolt, 1948). It is of some significance that Case 1 did in fact have other congenital lesions and that megakaryocytes appeared in normal numbers coincident with recovery. The familial incidence in Cases 3 and 4 is also compatible with a congenital aetiology, although in the first of these the finding of a platelet auto-antibody suggests some immune mechanism, as is often seen in chronic I.T.P. In the latter condition, megakaryocytes are characteristically plentiful in the marrow, and their paucity must be a strong point against this diagnosis. However, in two reported cases (Whitney and Barritt, 1942; Finn, 1944) of neonatal purpura occurring in infants of mothers with I.T.P., presumed but not proved to be due to an immune mechanism, the infant's marrow was found to be deficient in megakaryocytes at autopsy. There was 
no suspicion of I.T.P. in the history of the mother of Case 3; she was also the mother of Case 4 and in each pregnancy her platelet count was normal. In both infants the somewhat late onset of symptoms (the fourth and eleventh day after birth respectively) also suggests that the cause was not related directly to the mother. It must be admitted that the serum of the elder child in this family (Case 4) was not tested for platelet antibodies at or shortly after birth. There was only a negative result at $3 \frac{1}{2}$ years of age, long after the thrombocytopenia had subsided, and this must be regarded as inconclusive. It is possible that these two children could be instances de novo of familial idiopathic thrombocytopenic purpura, although the marrow finding in the younger child is against this, and it is very unusual for this disease to manifest itself at such an early age.

Most cases of congenital hypoplastic thrombocytopenia recover rapidly and even spontaneously, although the administration of prednisolone in Cases 1 and 2 appeared to result in a rapid rise in the platelet count. Even in Case 3, where the megakaryocytic hypoplasia was associated with the demonstrable presence of a platelet antibody, recovery was rapid and unaided. The degree of megakaryocytic hypoplasia is probably an important factor in recovery since in the virtually complete amegakaryocytic types described by Greenwald and Sherman (1929), Bell, Mold, Oliver and Shaw (1956) and Emery, Gordon, Rendle-Short, Varadi and Warrack (1957), the outcome was fatal, there being no response to cortisone or splenectomy where this was tried, and there were other congenital malformations. In spite of the good prognosis in congenital thrombocytopenic purpura, provided the infant has survived the trauma of birth and provided the condition is not secondary to some infection, there is always the remote risk of the serious complication of intracranial haemorrhage, particularly when the platelet count is at a very low level and showing no tendency to rise. It is this hazard which makes treatment important. The chances of therapeutic success with either cortisone or splenectomy will depend ultimately on the degree of megakaryocytic hypoplasia and should be tried in this order. If megakaryocytes are completely lacking no beneficial effect can be anticipated and splenectomy is contraindicated.

\section{Summary}

Four babies with congenital thrombocytopenic purpura, whose mothers were apparently normal, have been reported. No agglutination was demonstrable between the sera of these mothers and the platelets of their babies. A platelet agglutinin was found in one infant. The marrow findings in three of the cases pointed to a congenital hypoplasia of the megakaryocytes, and in one instance a return to normal numbers and morphology concurrent with recovery was noted.

We wish to thank Dr. C. F. Harris and Dr. A. W. Franklin of the Paediatric Department of St. Bartholomew's Hospital, London, for permission to record these cases which were under their care, and we are also indebted to Miss B. Kirk for technical assistance in the haematological investigations.

\section{REFERENCES}

Bell, A. D. Mold, J. W., Oliver, R. A. M. and Shaw, S. (1956). Study of transfused platelets in a case of congenital hypoplastic thrombocytopenia. Brit. med. J., 2, 692 .

Emery, J. L., Gordon, R. R., Rendle-Short, J., Varadi, S. and Warrack, A. J. N. (1957). Congenital amegakaryocytic thrombocytopenia with congenital deformities and a leukemoid blood picture in the newborn. Blood, $12,567$.

Finn, W. F. (1944). Thrombocytopenic purpura in pregnancy: Review of the literature with a report of 3 cases. Amer. J. Obstet. Gynec., 48, 497.

Goldstein, L. S. (1947). Congenital essential thrombopenic purpura: Report of the condition in fraternal twins. Amer. J. Dis. Child., 73, 575.

Greenwald, H. M. and Sherman, I. (1929). Congenital essential thrombocytopenia. Ibid., 38, 1245.

Hauser, F. (1948). Über hereditäre und symptomatische congenitale Thrombopenie. Ann. pediat. (Basel), 171, 86.

Landolt, R. F. (1948). Kongenitale (neonatale) Thrombopenien. Helv paediat. Acta, 3, 3.

Morris, M. B. (1954). Thrombocytopenic purpura in newborn. Arch. Dis. Childh., 29, 75.

Robson, H. N. and Walker, C. H. M. (1951). Congenital and neonatal thrombocytopenic purpura. Ibid., 26, 175.

Sanford, H. N., Leslie, E. I. and Crane, M. M. (1936). Congenital thrombocytopenia. Amer. J. Dis. Child., 51, 1114.

Stefanini, M. and Dameshek, W. (1955). The Hemorrhagic Disorders. Grune and Stratton, New York.

Urbanski, A. X. and Hutner, C. I. (1942). Thrombopenic purpura complicating pregnancy: Treatment by splenectomy resulting in clinical cure and followed by 3 full term pregnancies. J. Amer. med. Ass., $120,754$.

Whitney, L. H. and Barritt, A. S. (1942). Spontaneous and hereditary thrombopenic purpura in a mother and 2 sons. Amer. $J$. Dis. Child., 64, 705 . 